\title{
PROFILE OF DRUG ALLERGY PATTERN- AN EXPERIENCE FROM KERALA
}

\author{
Venugopal Panicker', Shajahan Purathel Sulaiman²
}

${ }^{1}$ Additional Professor, Department of Pulmonary Medicine, Government TD Medical College, Alappuzha. ${ }^{2}$ Associate Professor, Department of Pulmonary Medicine, Government TD Medical College, Alappuzha.

ABSTRACT

\section{BACKGROUND}

Drug allergy is a commonly encountered clinical problem accounting to significant morbidity and mortality. Identifying the offending drugs and avoidance is essential to avert serious consequences.

\section{MATERIALS AND METHODS}

This study was conducted to identify the skin sensitivity to various drugs in patients with history of drug allergy and to study the regional pattern of drug allergy in Kerala. 200 patients with history of allergy to at least one drug in the past were selected for the study. Allergy testing with 44 common drugs was performed in the above patients by skin prick test (SPT) method.

\section{RESULTS}

Most common offending drugs identified were ranitidine, quinolones, ondansetron, piroxicam, scoline, cephalosporins, paracetamol, atracurium, diclofenac and diazepam in the descending order of frequency.

\section{CONCLUSION}

Skin prick testing is an efficient and safe method to identify drug allergy. Most patients with drug allergy are allergic to multiple drugs.

\section{KEYWORDS}

Drug Allergy, Allergy Testing, IgE, Skin Prick Testing (SPT).

HOW TO CITE THIS ARTICLE: Panicker VG, Sulaiman SP. Profile of drug allergy pattern- An experience from Kerala. J. Evolution Med. Dent. Sci. 2017;6(28):2334-2336, DOI: 10.14260/Jemds/2017/502

\section{BACKGROUND}

Drug allergy is a frequent form of allergy and it is often a difficult problem faced by clinicians in everyday practice. It can manifest through a spectrum of symptoms ranging from mild pruritus and rashes at one end to severe anaphylaxis and even death at the other end. Identifying the offending drugs and avoidance is one of the most important measures which may help in the management of drug allergy. Skin prick testing is the most reliable method of identifying drug allergy as per current literature. ${ }^{1}$

\section{MATERIALS AND METHODS}

\section{Objectives}

This descriptive study was conducted at Alappuzha, a district of Kerala, India with the following objectives-

1. To study skin sensitivity to various drugs in patients with history of some drug allergy.

2. To identify the regional pattern of drug allergy in Kerala.

\section{Inclusion Criteria}

Patients with history of some form of drug allergy who were referred to the allergy clinic were selected for the study.

Financial or Other, Competing Interest: None.

Submission 27-02-2017, Peer Review 22-03-2017,

Acceptance 30-03-2017, Published 06-04-2017.

Corresponding Author:

Dr. Venugopal Panicker,

Additional Professor,

Department of Pulmonary Medicine,

Government TD Medical College,

Alappuzha.

E-mail: venuparijatham@gmail.com

DOI: $10.14260 /$ jemds $/ 2017 / 502$

\section{Exclusion Criteria}

1. Patients with age less than 10 years and more than 60 years.

2. Patients with extensive eczema were not included, because of difficulty in doing skin testing in such patients.

3. Patients with adverse drug reactions other than true allergy, e.g.- serum sickness, toxic epidermal necrosis, Stevens-Johnson syndrome (SJS), and drug reaction/rash with eosinophilia and systemic symptoms (DRESS), etc. were excluded, since skin prick test is effective in diagnosing only IgE mediated drug allergy.

4. Certain drugs like morphine and azithromycin were excluded from this study because morphine can cause local histamine release and so produce wheal even in absence of real allergy. Similarly, azithromycin causes severe local skin reaction leading to necrosis and ulceration even in non-allergic individuals.

5. Patients with gross dermatographism were excluded from the study.

6. Since the study was aimed to identify the regional pattern of drug allergy, patients outside Kerala were excluded from the study.

\section{Methodology}

A detailed history of past incidences of drug allergy was taken in all patients. Pre-test pattern of allergy obtained from history and old documents were shown in table 1 . The patient's atopic status was also evaluated by probing into a history of any other allergies in the past like asthma, allergic rhinitis, skin allergy or food allergy.

Total serum IgE was estimated in all patients by fully automated Bi-directional Interfaced Chemiluminescent immunoassay method to assess the atopic status. Allergy 
testing with 44 commonly used drugs which were available in injectable form was performed in the above patients by skin prick test method. List of the drugs tested are given in table 2 . Skin testing and reading were conducted as per criteria laid by American Academy of Allergy Asthma and Immunology ${ }^{2}$ (AAAAI) and British Society for Allergy and Clinical Immunology ${ }^{1}$ (BSACI) guidelines for the management of drug allergy. Patients were asked not to take antihistamines or steroids prior to 72 hours of testing. Tests were carried out at therapeutic concentrations except for drugs possessing intrinsic histamine-releasing activity (e.g. atracurium) in which case a dilution of $1 / 10$ to avoid false-positive results was used. The reaction was checked at 15-20 minutes. Buffered saline was used as negative control and histamine as positive control. A positive is a wheal size of diameter of 3 $\mathrm{mm}$ or greater than negative control, surrounded by a flare.

\section{RESULTS}

Total number of patients: 200 .

\section{Sex Distribution}

Female -122 (61\%), male -78 (39\%). Male to female ratio being 1:1.56. This finding is in agreement with the literature that drug allergy is more common among females. ${ }^{3}$

\section{Age}

Ranged from 10 to 60 with an average of 42 years.

Atopy and Serum IgE: 124 patients (62\%) had history of some form of atopy. Serum IgE levels: The serum IgE values ranged from $24 \mathrm{IU} / \mathrm{mL}$ to $2471 \mathrm{IU} / \mathrm{mL}$, with an average value of $324 \mathrm{IU} / \mathrm{mL} .81$ patients (55.5\%) had Serum IgE levels more than upper limit of normal. (The normal value of IgE in adult is less than $158 \mathrm{IU} / \mathrm{mL}$.) This proves that drug allergy is more common among atopic individuals. According to current literature, atopic predisposition does not increase the likelihood of a reaction but may contribute to a more severe allergic reaction. 4,5

Table 1. Pre-test pattern of allergy obtained from history and old documents were shown in table 1.

\begin{tabular}{|c|c|}
\hline Drug & Number of Patients Allergic \\
\hline Penicillin & $34(17 \%)$ \\
\hline Sulphonamides & $30(15 \%)$ \\
\hline Paracetamol & $26(13 \%)$ \\
\hline Ranitidine & $20(10 \%)$ \\
\hline Ibuprofen & $15(7.5 \%)$ \\
\hline Diclofenac & $15(7.5 \%)$ \\
\hline $\begin{array}{l}\text { Other NSAIDS (name not } \\
\text { known) }\end{array}$ & $18(9 \%)$ \\
\hline Multiple drugs & $54(27 \%)$ \\
\hline Unknown drug & $64(32 \%)$ \\
\hline
\end{tabular}

\section{Pattern of Allergy}

All the patients except one were found to be allergic to at least one of the drugs tested (99.5\%).151 patients (75.5\%) had allergy to more than one drug. Only 48 patients (24\%) were found to be allergic to a single drug. While 39 were allergic to two drugs, 26 were allergic to three drugs and the rest 86 patients $(43 \%)$ were allergic to more than three drugs. One patient was found to be allergic to none of the drugs tested.

Most common offending drugs identified were ranitidine (79\%), quinolones $(70 \%)$, ondansetron $(43 \%)$, piroxicam (38\%), scoline (37\%), cephalosporins (36\%), paracetamol (36\%), atracurium (29.5\%), diclofenac (20\%) and diazepam $(19.5 \%)$ in the descending order of frequency.

No patients were found to be allergic to heparin, furosemide, theophylline, metoclopramide, aminoglycosides, cloxacillin, terbutaline, propofol, fentanyl, neostigmine, steroids and antihistamines. Out of the 200 patients, none developed significant immediate or late complications following SPT. No relation could be established between age of the patient and the number or variety of drugs. Similarly, no relation could be established between the level of Serum IgE and number of allergic drugs.

\begin{tabular}{|c|c|c|c|c|c|}
\hline Sl. No. & Drugs & No. of Patients found to be Allergic & Sl. No. & Drugs & No. of Patients found to be Allergic \\
\hline 1 & Ranitidine & $158(79 \%)$ & 23 & Bupivacaine & $5(2.5 \%)$ \\
\hline 2 & Quinolones & $140(70 \%)$ & 24 & Midazolam & $4(2 \%)$ \\
\hline 3 & Ondansetron & $86(43 \%)$ & 25 & Dopamine & $4(2 \%)$ \\
\hline 4 & Piroxicam & $76(38 \%)$ & 26 & Pantoprazole & $3(1 \%)$ \\
\hline 5 & Scoline & $74(37 \%)$ & 27 & Lignocaine & $2(1 \%)$ \\
\hline 6 & Cephalosporins & $72(36 \%)$ & 28 & Pancuronium & $2(1 \%)$ \\
\hline 7 & Paracetamol & $72(36 \%)$ & 29 & Rocuronium & $2(1 \%)$ \\
\hline 8 & Atracurium & $59(29.5 \%)$ & 30 & Thiopentone & $2(1 \%)$ \\
\hline 9 & Diclofenac & $40(20 \%)$ & 31 & Glycopyrrolate & $1(0.5 \%)$ \\
\hline 10 & Diazepam & $39(19.5 \%)$ & 32 & Butorphanol & 0 \\
\hline 11 & Mephentermine & $35(17.5 \%)$ & 33 & Heparin & 0 \\
\hline 12 & Atropine & $35(17.5 \%)$ & 34 & Furosemide & 0 \\
\hline 13 & Ketorolac & $34(17 \%)$ & 35 & Theophylline & 0 \\
\hline 14 & Ketamine & $31(15.5 \%)$ & 37 & Aminoglycosides & 0 \\
\hline 15 & Dicyclomine & $30(15 \%)$ & 38 & Cloxacillin & 0 \\
\hline 16 & Tramadol & $30(15 \%)$ & 39 & Terbutaline & 0 \\
\hline 17 & Vecuronium & $21(10.5 \%)$ & 40 & Propofol & 0 \\
\hline 18 & Promethazine & $21(10.5 \%)$ & 41 & Fentanyl & 0 \\
\hline 19 & Prochlorperazine & $18(9 \%)$ & 42 & Neostigmine & 0 \\
\hline 20 & Ampicillin & $14(7 \%)$ & 43 & Steroids & Antihistamines \\
\hline 21 & Metronidazole & $12(6 \%)$ & $11(5.5 \%)$ & \multicolumn{2}{l|}{} \\
\hline 22 & Dobutamine & Table 2. List of Drugs Tested and Frequency of Allergy to Various Drugs \\
\hline
\end{tabular}




\section{DISCUSSION}

Drug allergy is a common problem encountered by patients and physicians alike worldwide. Patients are often denied the benefits of life saving drugs due to fear of allergy, once they report to be allergic to any drugs. Skin prick testing is an efficient and safe method of allergy testing to identify drug allergy and thereby avoiding such drugs.

There is limited literature on the pattern and frequency of drug allergy worldwide. This study aims at identifying this pattern of drug allergy in Kerala. In order of prevalence, the most common allergic drugs identified were ranitidine (79\%), quinolones $(70 \%)$, ondansetron $(43 \%)$, piroxicam (38\%), scoline (37\%), cephalosporins $(36 \%)$, paracetamol (36\%), atracurium (29.5\%), diclofenac $(20 \%)$ and diazepam (19.5\%).

Skin prick test, if done by a trained person with adequate precautions to handle emergencies is a safe method to identify drug allergy. Identifying allergic drugs would be of extreme benefit for the patient in avoiding allergic drugs as well as using non-allergic drugs without fear. It will also help the physician to choose non-offending drugs in managing the clinical conditions with confidence. Prior knowledge about the offending drugs will also help the treating physician and the hospital to avoid possible medicolegal issues in the future. Awareness about the prevalence of drug allergy also helps in cautious use of such drugs, especially in atopic individuals. Patients with history of allergy to any single drug should be evaluated for identifying all commonly used drugs, since incidence of multiple drug allergies is high. This is especially so if the patient is undergoing any surgical procedures.

\section{CONCLUSION}

1. Skin prick testing is an efficient and safe method to identify drug allergy.
2. Most patients with drug allergy are allergic to multiple drugs (84\%).

3. Incidence of drug allergy is high among atopic individuals.

4. Drug allergy is more common among females.

5. Most common allergic drugs identified were ranitidine (79\%), quinolones (70\%), ondansetron (43\%), piroxicam (38\%), scoline (37\%), cephalosporins (36\%), paracetamol (36\%), atracurium (29.5\%), diclofenac $(20 \%)$ and diazepam (19.5\%) in the descending order of frequency.

6. Even though ampicillin and cloxacillin belong to penicillin group, allergy to these drugs are rare.

7. There is no apparent relation between age and sex of the patient with drug allergy.

\section{REFERENCES}

[1] Mirakian R, Ewan PW, Durham SR, et al. BSACI guidelines for the management of drug allergy. Clin Exp Allergy 2009;39(1):43-61.

[2] Bernstein IL, Li JT, Bernstein DI, et al. Allergy diagnostic testing: an updated practice parameter. Ann Allergy Asthma Immunol 2008;100(3 Suppl 3):S1-148.

[3] Wiffen P, Gill M, Edwards J, et al. Adverse drug reactions in hospital patients: a systematic review of the prospective and retrospective studies. Bandolier Extra 2002:1-15.

[4] Haddi E, Charpin D, Tafforeau M, et al. Atopy and systemic reactions to drugs. Allergy 1990;45(3):2369.

[5] Co Minh HB, Bousquet PJ, Fontaine C, et al. Systemic reactions during skin tests with beta-lactams: a risk factor analysis. J Allergy Clin Immunol 2006;117(2):466-8. 